\title{
Dental caries: Strategies to control this preventable disease
}

\author{
Andrew Rugg-Gunn \\ School of Dental Sciences \\ Newcastle University, UK \\ Corresponding author: \\ Andrew Rugg-Gunn, Morven \\ Boughmore Road, Sidmouth \\ Devon EX10 8SH, UK \\ andrew@rugg-gunn.net \\ Tel.: + 441395578746
}

Received: 27 January 2013

Accepted: 19 March 2013

Copyright (C) 2013 by

Academy of Sciences and Arts

of Bosnia and Herzegovina.

E-mail for permission to publish:

amabih@anubih.ba

\begin{abstract}
Objective. To provide a brief commentary review of strategies to control dental caries. Dental decay is one of man's most prevalent diseases. In many counties, severity increased in parallel with importation of sugar, reaching its zenith about 1950s and 1960s. Since then, severity has declined in many countries, due to the wide use of fluoride especially in toothpaste, but dental caries remains a disease of medical, social and economic importance. Within the EU in 2011, the cost of dental treatment was estimated to be $€ 79$ billion. The pathogenesis is well understood: bacteria in dental plaque (biofilm) metabolise dietary sugars to acids which then dissolve dental enamel and dentine. Possible approaches to control caries development, therefore, involve: removal of plaque, reducing the acidogenic potential of plaque, reduction in sugar consumption, increasing the tooth's resistance to acid attack, and coating the tooth surface to form a barrier between plaque and enamel. At the present time, only three approaches are of practical importance: sugar control, fluoride, and fissure sealing. The evidence that dietary sugars are the main cause of dental caries is extensive, and comes from six types of study. Without sugar, caries would be negligible. Fluoride acts in several ways to aid caries prevention. Ways of delivering fluoride can be classed as: 'automatic', 'home care' and 'professional care': the most important of these are discussed in detail in four articles in this issue of the Acta Medica Academica. Conclusion. Dental caries is preventable individuals, communities and countries need strategies to achieve this.
\end{abstract}

Key words: Dental caries, Diet, Nutrition, Fluoride, Public health strategies.

\section{Introduction}

Dental decay is commonly called dental 'caries', from the Latin word meaning rottenness. It is one of the most common of chronic diseases and is of medical, social and economic importance. Yet its cause is well known and methods of preventing its occurrence and progression have been developed and many are practiced. The pre- ventable is not yet prevented. The aim of this article is to provide a commentary review of strategies to control dental caries.

\section{Size of the problem}

While ancient civilisations experienced dental decay, it is largely a 'modern' disease. Dentists are lucky that teeth survive the lon-

\footnotetext{
${ }^{\star}$ The author is Professor emeritus, Newcastle University. No support was provided for the preparation of this paper.
} 
gest of any tissue after death: we do not have to rely on contemporary accounts of disease prevalence, we dig up our ancestors. The results of these archaeological surveys reveal that experience of dental caries was low until the nineteenth century, when it rose sharply in several European countries. This steady increase during the century 1850 to 1960 coincided with increasing importation of cane sugar from the Americas. In Britain, a defining moment occurred around 1900 when 'poor teeth' was the most important cause of rejection of volunteers for military service. This became a 'wake-up call' for those concerned with public health. For much of Europe and other 'developed' countries, 1960 to 1970 became the turning-point; after 1970 the epidemic of dental caries reduced considerably (1). As will be discussed below, this decline has been due largely to the widespread use of fluoride. Although there has been a very welcome decline in the bur- den of dental caries, it remains one of man's most prevalent diseases (2). Elsewhere in the world, dental caries experience has increased (Figure 1) so that, for children for example, the global average has remained almost unchanged for 30 years.

The effect of dental caries is cumulative with age, and Petersen and colleagues (3) point out that the worldwide average for people aged 65 years or more, is 22 teeth either decayed, missing or filled (out of 32 teeth). Dental caries is the most important oral disease and is of medical, social and economic importance. It is now recognised that dental caries cannot be considered in isolation - its occurrence and control depends on social environment and behaviour, at the levels of the individual and the broader community. It is recognised increasingly that oral diseases have negative impacts on general health. Table 1 shows that, in an area of north-east England without water fluoridation, over a

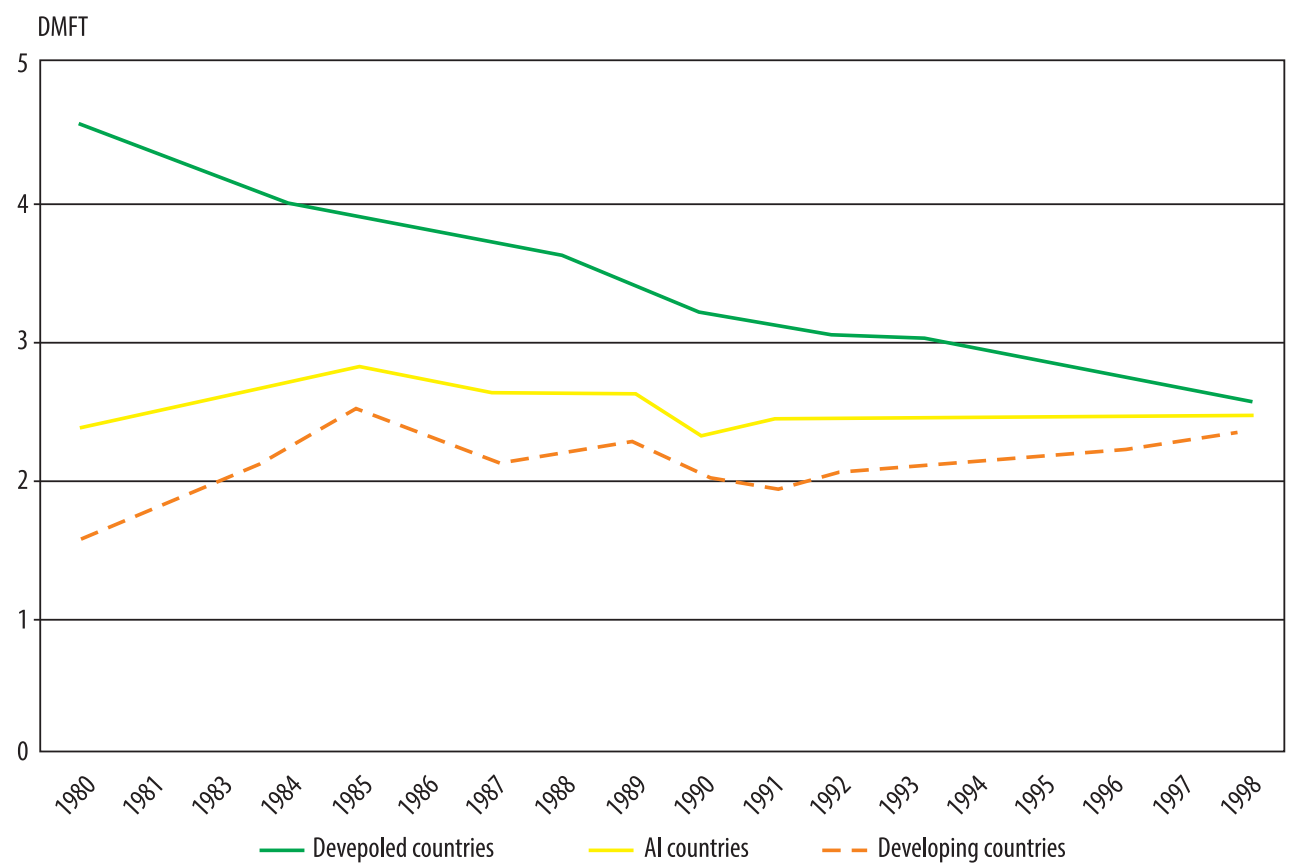

Figure 1 Dental caries severity (decayed, missing and filled teeth) in 12-year-olds between 1980 and 1998, in developed countries (top line), all countries (middle line) and developing countries (bottom line) (2). 
Table 1 Percentage of 5-year-old children living in Urban and Rural areas in north-east England in who had (a) one or more dental abscess at the time of examination (point prevalence), (b) lifetime experience of one or more episode of toothache, or general anaesthetic for dental extraction. Data collected in Non-fluoridated (<0.1 mg F/litre) and Fluoridated (1 mg F/litre) communities in 1975 (4)

\begin{tabular}{lllll}
\hline \multirow{2}{*}{ Experiences } & Urban & Rural \\
\cline { 2 - 5 } & Non-fluoridated & Fluoridated & Non-fluoridated & Fluoridated \\
\hline Dental abscess (\%) & 3 & 1 & 5 & 0 \\
Toothache (\%) & 40 & 22 & 38 & 17 \\
General anaesthetic (\%) & 34 & 18 & 22 & 7 \\
\hline
\end{tabular}

third of 5 year-olds had experienced toothache and a quarter to a third had had one or more general anaesthetics for dental extractions due to dental decay (4). In many countries, tooth extraction because of dental caries is the most common reason for general anaesthetics in childhood.

At the Sixtieth World Health Assembly in May 2007, a Resolution, confirmed by the Member States, emphasised that oral disease is a serious public health problem and that its impact on individuals and communities in terms of pain and suffering, impairment of function and reduced quality of life, is considerable (5). Oral disease is the fourth most expensive disease to treat. Globally, the greatest burden of oral diseases lies on disadvantaged and poor populations. The first action point in the Resolution - "urges Member States to adopt measures to ensure that oral health is incorporated as appropriate into policies for the integrated prevention and treatment of chronic noncommunicable and communicable diseases, and into maternal and child health policies." This acknowledges that most oral disease and chronic diseases have common risk factors, for example, unhealthy environments and behaviours, particularly widespread use of tobacco and excessive consumption of alcohol and sugar.

More locally, a recent report on 'The state of oral health in Europe' (6) summarised the impact of oral diseases within the EU. Discussing the economic impact of oral diseas- es in Europe, the first summary point was: "Oral diseases remain a major public health issue for high-income countries, where expenditure on treatment often exceeds that for other diseases, including cancer, heart disease, stroke, and dementia. This is disturbing, given that much of the oral disease burden in high-income countries is due to dental caries and its complications, and this is preventable through the use of fluoride and other cost effective measures". The report estimates that the annual cost in 2011 of dental treatment within the 27 member states of the current EU was about $€ 79$ billion. Dental disease is one of the frequent reasons for absence from school. The aetiology of these diseases is very well known, yet they are not yet prevented because of the seemingly insurmountable hurdles of commercial pressure, politics, local environments and personal behaviour.

\section{Pathogenesis}

Ancient civilizations in China, Mesopotamia and Greece believed that dental decay was caused by worms and therefore had to be treated by fumigation. This view persisted up to the time when Antony van Leuwenhoek observed, through his newly developed microscope, little worms (bacteria) in material taken from a carious tooth. Pasteur showed that sugars could be fermented to acids by micro-organisms, and Magitot demonstrated that the acids produced by 
fermentation of sugars were capable of destroying tooth enamel in vitro. In 1890, WD Miller published his chemo-parasitic theory of caries aetiology. This remains the simple explanation of the caries process: bacteria in dental plaque metabolise dietary sugars to acids which then dissolve dental enamel and dentine. A modern refinement is that the process is not continuous but cyclical. Periods of acid attack and mineral loss are interspersed with periods of remineralisation, and major tooth destruction (a cavity) only occurs if mineral loss is greater than healing. The major force to remineralise tooth tissue is saliva, which is supersaturated with calcium. This becomes clinically evident in patients with very low salivary flow (hyposalivation) - perhaps due to radiation to the head and neck or drugs - who suffer rapid, severe dental caries. The most important action of fluoride is to encourage remineralisation of demineralised enamel and dentine. Although the phrase 'dental plaque' is still used extensively, it is more correct to use the term 'dental biofilm' - the important thing is that it is $70 \%$ bacteria, forms within days if teeth are not cleaned, and adheres very well to tooth surfaces, thus keeping acid metabolites close to the tooth surface.

\section{Possible approaches to caries prevention}

Since the pathogenesis of dental caries is well understood, strategies to prevent caries development would seem to be relatively simple. Either the attacking forces can be reduced or the host resistance can be enhanced. Ways to decrease to attacking forces include: removal of dental plaque (dental biofilm), alteration of dental plaque so that it is less able to metabolise dietary sugars to acids, neutralise the acids within plaque, and remove or reduce dietary sugars. Ways to enhance host resistance include: reduce enamel's solubility in acid, increase the po- tential for remineralisation of demineralised enamel, cover enamel surfaces so as to put a barrier between dental plaque and enamel. All of these, and more, have been tried.

Toothbrushing is an accepted social habit, making teeth more attractive, removing mouth odours and helping to prevent periodontal disease. If done very well, toothbrushing is able to remove plaque sufficiently to reduce caries development. But the majority of people do not achieve this standard and studies have shown that brushing teeth, per se, does not reduce caries development; it is the fluoride in the toothpaste used which has the caries-preventive effect (7) (vide infra).

Unlike classical infectious diseases, which are caused by microbial pathogens, dental caries is caused by the resident oral microflora. There are contrasting opinions as to the use of chemical agents in the prevention and treatment of dental caries. Those in favour believe that chemical agents can be an adjunct to toothbrushing and dental flossing, while those opposed argue that such agents may disturb the ecological balance within the oral cavity and that resistant strains may emerge (8). Nevertheless, many chemical agents have been studied, the most successful being chlorhexidine. This cationic antiseptic is bacteriocidal and, being strongly surfaceactive, is particularly good at preventing microbial colonisation of clean enamel. Commercial mouthrinses commonly contain $0.2 \%$ chlorhexidine. Although such mouthrinses are effective in aiding plaque control, they are not used extensively because they discolour teeth and some tooth-coloured restorations, and alter taste sensations.

Other approaches have been the use of probiotics and immunisation. Probiotics are "live microorganisms which, when administered in adequate amounts, confer a health benefit on the host" and many species and strains have been studied in relation to oral health (9). Their action is to interfere with 
attachment and colonisation of cariogenic bacteria and to inhibit sugar fermentation, and there is some evidence that they confer some benefit. The vehicle used is commonly milk and it is fortunate that the action of probiotics and fluoride are additive (10). There was much work on immunisation against dental caries about 30 years ago but virtually none during the past 15 years. Partial protection only was achieved in monkeys following quite extensive courses of inoculation, but the possibility of cross-reaction with heart tissues made further research uninviting. A central problem is that no one plaque organism is uniquely cariogenic. The approach of reducing dietary sugars will be discussed below.

Research into increasing enamel's resistance to dental caries is nearly a century old. Eighty years ago, during the golden era of vitamin research, it was believed that dental caries was a deficiency disease, and dietary vitamins and minerals have been studied extensively (11). There is some evidence that vitamin $\mathrm{D}$ is protective and some evidence that caries development is inversely related to hardness of water, but any of these effects is dwarfed by the positive effect of fluoride. The unique ability of fluoride to protect against caries seems to be, in part, because it acts in several ways, all beneficial (12). First, the appropriate dose of fluoride during tooth development in childhood renders the enamel more acid-resistant - fluorapatite is less soluble than hydroxyapatite. Second, there is some evidence that fluoride alters the shape of the fissures in tooth crowns during tooth formation: this is somewhat controversial and likely to be unimportant. Third, an adequate concentration of fluoride within plaque helps to reduce demineralisation and enhance remineralisation of enamel during the dynamic caries process: this ability to encourage remineralisation is now thought to be fluoride's most important action. Fourth, adequate concentrations of fluoride within plaque reduce the ability of plaque to metabolise sugars to acids. The various ways in which fluoride can be used in caries prevention are discussed below.

If you can make saucepans 'non-stick', why not teeth? Of the various 'coatings' studied, 'fissure-sealants' have stood the test of time and are used extensively. The key to their success was the development of the 'acid-etch' technique in the 1950s (13) whereby the enamel surface is etched, washed and dried before resin is flowed onto the etched enamel and set hard. It is only practical to seal the fissures and pits in teeth since these are the most at risk sites. It is an exacting technique carried out by professional staff and is thus relatively expensive (compared with home care or community preventive methods) but the large number of trials indicate high retention rates for sealants and, thus, substantial caries prevention.

In conclusion, a great number of approaches to caries prevention have been tried. At the present time, only three are of practical importance - control of dietary sugars, fluoride and fissure-sealing. Currently, research into genetic factors associated with dental caries is active: certain genes have been shown to be associated with protection against caries (14) but the practical significance of these findings is, as yet, uncertain.

\section{Dietary control of dental caries}

Diet advice to prevent and control dental caries has a long history. For example, the ancient Greeks warned against eating overripe figs. However, the last century has seen much research in this area.

\section{Dental caries a deficiency disease?}

Advice about healthy eating, about fifty years ago, urged mothers to give their young children diets rich in calcium and vitamin $\mathrm{D}$, so that they would form strong healthy bones and teeth: the inference was that these 
'strong teeth' would be less likely to decay. Although this is sound advice as far as the skeleton is concerned, there has always been little evidence to substantiate the view that good nutrition in early life helps to prevent dental decay by a systemic effect. This certainly does not mean that good nutrition should be discouraged, it merely reflects the current view that, in developed countries, diet has a much greater effect locally in the mouth on erupted teeth than it does pre-eruptively (11). The evidence supporting the pre-eruptive role of diet now centres around just two aspects - vitamin D and fluoride (11) (vide infra). Under-development of salivary glands in malnourished children results in hyposalivation which, in turn, increases risk of dental caries - but this is a post-eruptive effect.

Two key experiments were published in the 1950s. In the first experiment (15), rats were fed a cariogenic (caries-inducing) diet either conventionally or by stomach tube. Those fed by stomach tube did not develop dental caries, even in a sub-group whose salivary glands had been removed, in contrast to extensive caries development in the rats

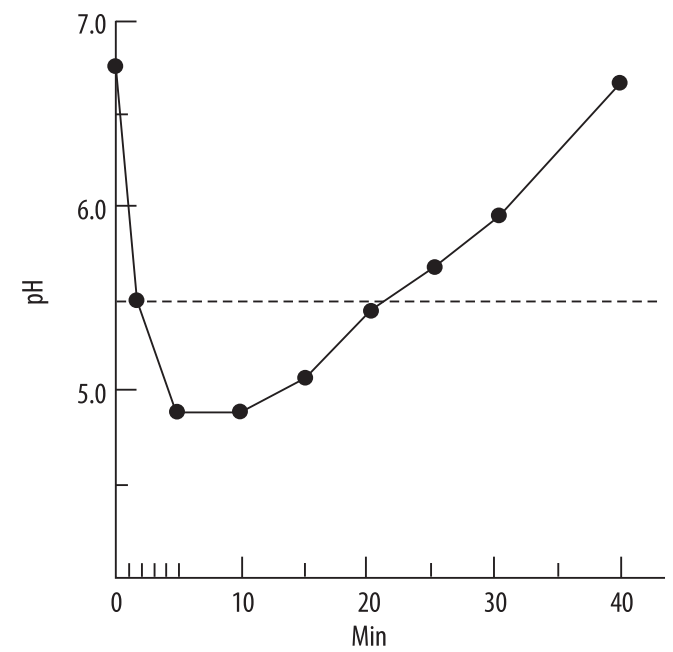

Figure 2 The Stephan curve. Plot of the $\mathrm{pH}$ within dental plaque at time-points after exposure to sugar. The interrupted horizontal line at $\mathrm{pH} 5.5$ marks the critical $\mathrm{pH}$ below which enamel is at risk of dissolution. fed conventionally. In the second experiment (16), rats were fed a cariogenic diet but half of them were kept germ-free while the other half lived conventionally with a mixed microbial flora. No caries developed in the germfree rats in contrast to extensive decay in the conventionally reared animals. Thus, it became quite clear that caries development depended on microflora and food in the mouth. A third important series of experiments was published by Stephan, initially in 1940 (17). Figure 2 shows what has become known as the 'Stephan curve'. Laboratory experiments had shown that enamel dissolves when the $\mathrm{pH}$ falls below about 5.5. Stephan showed that the $\mathrm{pH}$ within dental plaque falls rapidly after exposure to sugar, from a resting value of about 7 , to values below 5.5 , taking about 40 minutes to return to its resting value. The slow rise back to the resting value is due to saliva, both removing the sugars and neutralising the acids, as became apparent when salivary glands were cupped. Variations of Stephan's curve experiments are still being used, albeit using more advanced methods of recording $\mathrm{pH}$ within plaque, to test the cariogenic potential of foods (vide infra).

\section{Sugars and dental caries - types of study providing the evidence}

One of the key publications which turned opinion away from 'caries is a deficiency disease' to the modern view that dietary sugar is of paramount importance in caries development appeared in 1940 (18). Since then, much research has confirmed this view. Because this has been disputed by the sugar and sugar-related industries, the evidence base will be reviewed briefly. There are six types of study providing evidence on the relationship between diet and the development of dental caries (Table 2). The best source of evidence is studies of the occurrence of caries in human populations in relation to their diet. These studies are ei- 
ther observational (epidemiological) studies or interventional studies. The later provide stronger evidence but are fewer in number because of the practical and ethical difficulties of inviting large groups of subjects to adhere to strict diets for a long enough time for an effect on caries increment to be observed: this time period would normally be two to four years. There have been a large number of observational studies and, since the widespread use of computers, controlling for known confounding factors has become routine. The findings of these studies in human subjects (11) will be summarised.

Table 2 Types of investigation which provide evidence on the relationship between diet and the development of dental caries (11)

\begin{tabular}{l}
\hline Observational human studies \\
Interventional human studies \\
Animal experiments \\
Enamel slab experiments \\
Plaque pH experiments \\
Incubation (laboratory) experiments \\
\hline
\end{tabular}

There are many examples of populations who have traditionally had diets low in sugar but were then exposed to sugar through importation - for example, the Inuit, Bantu, east and west Africa, the island of Tristan da Cunha, and England. Dental caries experience was very low before exposure to sugar but high after exposure. There are groups of people who have had to consume diets low in sugar. An example is those with hereditary fructose intolerance who have to avoid consumption of fructose and sucrose: their caries experience is very low. During the Second World War, consumption of sugar was much reduced in several countries: records show that caries experience fell and then rose in parallel with sugar availability. In contrast, there are groups of people who have habitually consumed diets high in sugar - for example, workers in the confectionery industry, and children taking sugared oral medicines long-term - these have been observed to have high caries experience. There have been a large number of observational studies relating caries experience with diet in free-living children and adults. Most of these have been cross-sectional studies where caries experience and diet have been recorded concurrently once only. This is a relatively weak design since dental caries usually develops slowly over many years and diet may change from the time-period when it was influencing caries initiation to the time, several years later, when the diet was recorded. A better design is a longitudinal observational study (lasting a minimum of two years) where development of caries during that time-period is recorded and compared with diet recorded frequently during the same period of time. Possible confounding factors, such as use of fluorides and socio-economic status, can be recorded and included in data analysis. The vast majority of these studies have recorded positive associations between caries experience or development, and sugar intake - the latter may be specified as weight of sugar ingested, frequency of sugar ingestion, or consumption of specific sugar-rich food groups such as confectionery and sugared drinks.

The Vipeholm study (11) is one of the most famous in dental literature: it was carried out in a mental institute in Sweden between 1945 and 1953. There were eight test groups and one control group - the most aggressive regime was 24 toffees each day. The study would now be considered unethical. Caries development was very rapid in the groups consuming high amounts of sugar confectionery. In contrast, the Turku (Finland) study tested the effect of substituting normal dietary sugar (mainly sucrose) with fructose in one group and with xylitol in another group (11). The study lasted two years, 1972-74, and showed that caries development was virtually absent in the group consuming xylitol compared with the fairly 
high caries increment in the reference group who consumed their usual diet and the fructose group who developed slightly less decay than the reference group. Both the Vipeholm and the Turku studies are examples of intervention studies (11).

Most of the many animal experiments into the relation between diet and caries development were conducted before 1980. As mentioned above, they provided crucial evidence that sugar in the mouth is essential for caries development. In addition, they indicated that frequency of ingestion of sugars, independent of the amount of sugar per day, is strongly positively related to caries severity. Conversely, they also provided evidence that the amount of sugar ingested per day, independent of frequency, is positively related to caries severity.

'Enamel slab experiments' involve volunteer subjects wearing intra-oral appliances into which are inserted small pieces (slabs) of enamel: caries development in these slabs is measured when the subjects are asked to consume a variety of diets. The advantage is that very early carious changes can be observed (by a variety of instruments) so that experiments last only a few weeks. These experiments have added to the literature on the importance of frequency of exposure, different sugars and sugar-substitutes, and concentration of sugars.

Plaque $\mathrm{pH}$ studies are relatively simple to conduct and have been valuable in emphasising the risk of frequent sugar ingestion. They have also shown, for example, how the harmful effect of sugar ingestion might be negated by ingestion of cheese, since ingestion of cheese raises plaque $\mathrm{pH}$ rapidly. Fast-flowing saliva is alkaline ( $\sim \mathrm{pH} 7.5)$ and plaque $\mathrm{pH}$ experiments have shown that chewing sugarless gum induces salivary flow and raises plaque $\mathrm{pH}$, thus encouraging remineralisation of demineralised enamel.

Incubation experiments are the simplest type of study. They are laboratory-based ex- periments and valuable in the past for screening foods for their ability to produce acids in the presence of plaque bacteria and the ability of minerals (e.g. calcium) to prevent dissolution of enamel during exposure to acid.

In summary, the evidence that consumption of sugars causes dental caries is overwhelming: several types of study contribute to this body of evidence. Three aspects of sugar-eating will be discussed briefly.

\section{Type of Sugar}

The most common dietary sugars are sucrose, glucose, fructose, maltose and lactose. The sugar most commonly associated with dental caries is sucrose and, indeed, it has been labelled "the arch criminal of dental caries" (11). Some, but not all, of the many studies have suggested that sucrose is the most cariogenic sugar; certainly, none is more cariogenic than sucrose. There is extensive evidence that lactose is the least cariogenic sugar, and the cariogenicity of galactose is likely to be similar to lactose. From the practical viewpoint, there is probably little to be gained by substituting glucose, fructose or maltose, for sucrose.

\section{Frequency of consumption and the total amount consumed}

There is good evidence that frequency of ingestion of dietary sugars influences the severity of caries development. From the curve shown in Figure 2, it can be understood that demineralisation of enamel can occur each time sugar is ingested - if there are 10 sugar intakes a day, enamel stands to be attacked 10 times a day. The main conclusion from the Vipeholm study (vide supra) was that caries severity was strongly related to frequent ingestion of sugar. However, there is also much evidence that the amount of sugar ingested per day is positively related to caries severity. Most of the large number 


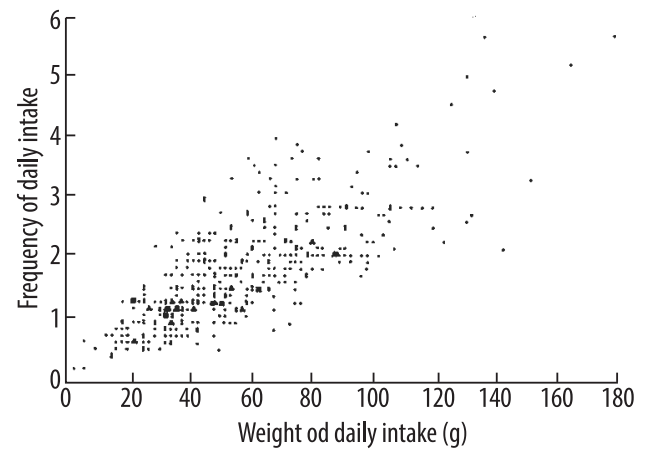

Figure 3 Plot of frequency of intake per day against the weight consumed per day, of confectionery, by 405 12-14-year-old children in north-east England (11).

of observational studies mentioned above, recorded amount of sugar, or sugar-rich foods, rather than frequency of ingestion. Carefully controlled animal experiments indicate that both variables - frequency and amount - are important. However, from the practical point of view, it probably does not matter if advice is to cut down frequency or amount since, in free-living people, there is a close relation between frequency and amount. Figure 3 is a plot of frequency of daily intake of confectionery against amount of confectionery consumed - the correlation was +0.77 .

\section{Sources of dietary sugars}

When giving advice about how to reduce sugar consumption, it is useful to know which part of the diet to target. First, it should be appreciated that some foods contain sugars naturally - these include milk (lactose), fruit and vegetables. Much sugar, though, is added to foods. These distinctions are important and have led to the definition of three types of sugar (19): (i) 'intrinsic sugars' - those within the structure of the food - e.g. fresh fruit and vegetables, (ii) 'milk sugars' - lactose, and (iii) 'non-milk extrinsic sugars' - sometimes called 'added sugars' and by WHO 'free sugars' (20). In a study of UK adolescents, over two-thirds of total sugars

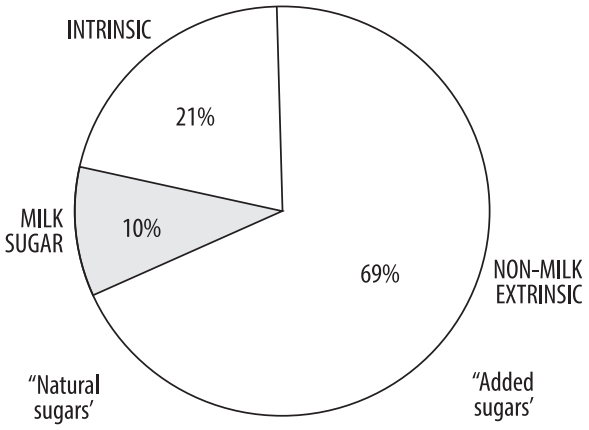

Figure 4 Dietary sugars intake in 12-14 year-old children living in north-east England (21). Mean daily intake of all sugars was $118 \mathrm{~g}$.

intake (90 g out of $118 \mathrm{~g}$ ) were non-milk intrinsic sugars as can be seen in Figure 4 (21).

Table 3 shows where these $90 \mathrm{~g}$ of nonmilk extrinsic sugars came from: $60 \%$ came from just two sources - confectionery and soft drinks. It should be noted that both of these are marketed for frequent consumption (snacking) and it is therefore not surprising that these two are targeted heavily in health promotion.

Table 3 Mean daily intake of non-milk extrinsic sugars (19) ('free sugars' (20); 'added sugars') from various dietary sources (as grams and as percentage) in a survey of 379 12-year-old English children in $1990(21)$

\begin{tabular}{ll}
\hline Various dietary sources & Added sugars (g; \%) \\
\hline Confectionery & $30(33)$ \\
Soft drinks & $24(27)$ \\
Table sugar & $11(12)$ \\
Biscuits and cakes & $10(11)$ \\
Sweet puddings & $5(6)$ \\
Breakfast cereals & $5(5)$ \\
Syrups and preserves & $2(2)$ \\
Other sources & $3(4)$ \\
All sources & $90(100)$ \\
\hline
\end{tabular}

\section{Dietary starch and dental caries}

It is not uncommon to see advice that dental caries is caused by 'dietary carbohydrates'. 
This is convenient for those promoting sugar products, as it takes the spotlight off dietary sugars. Dietary carbohydrates are, in broad terms, sugars and starches (excluding 'fibre'). A review of the evidence shows that dietary starches are not cariogenic, certainly compared with dietary sugars (11). If finely ground and heat-treated, starch can cause dental caries, but the amount is less than that caused by sugars. Cooked staple starchy foods, such as rice, potatoes and bread are of low cariogenicity. This view is supported by the WHO (20) who, when considering the strength of the evidence linking diet to dental caries, stated: (a) the evidence was 'convincing' for 'increased risk' of caries from 'amount of free sugars', and 'frequency of free sugars', and (b) there was 'no relationship' between dental caries and 'starch intake (cooked and raw starch foods, such as rice, potatoes and bread)'. The advice for oral health and general health are in agreement - increase consumption of staple starchy foods and decrease consumption of 'free' ('added' or non-milk extrinsic) sugars.

\section{Fruit and milk}

Fruit and milk contain sugars and, thus, could be considered cariogenic. To summarise the evidence (11): as eaten by humans, fresh fruit appears to be of low cariogenicity; sugared, fruit-flavoured drinks when used as a comforter are a significant cause of dental caries in young children; and there is insufficient evidence regarding pure fruit juice and caries, most of the studies looked at sugar-containing fruit-flavoured drinks. The WHO (20) classified the evidence as 'no relation' between 'whole fresh fruit' and dental caries.

Cow's (bovine) milk contains about $4.8 \mathrm{~g}$ lactose per $100 \mathrm{~g}$, thus having the potential to cause dental caries. However, milk also contains factors which protect teeth; these are mainly the high calcium content (about
$125 \mathrm{mg} / 100 \mathrm{ml}$ ) and proteins, particularly casein. The result is that milk is classed as non-cariogenic. In some experiments, milk has been shown to prevent dental caries and, indeed, WHO (20) classifies the strength of evidence relating milk to 'decreased risk' of caries as 'possible'. Thus, neither fruit nor milk are seen as a threat to oral health, and this is the reason for classifying them separately (as 'intrinsic' and 'milk' sugars) from non-milk extrinsic sugars.

\section{Non-sugar sweeteners}

A number of confectionery companies have tried to overcome the problem of sugarcontaining (and therefore cariogenic) products by substituting non-sugar sweeteners for sugars. Foremost amongst these have been manufacturers of chewing gum. The sweeteners used include sorbitol, xylitol, mannitol and maltitol (11). Evidence indicates that these sweeteners are non-cariogenic. It would appear that xylitol has better dental properties compared with the other sweeteners (22). The dental benefits of chewing sugarless gum (commonly containing xylitol) have been investigated extensively in Scandinavia, particularly Finland (23). This is promoted because the chewing stimulates saliva flow, thus encouraging remineralisation of dental enamel. WHO (20) classifies the strength of evidence for 'decreased risk' of caries for 'sugars-free chewing gum' as 'probable'. Manufacturers of carbonated soft drinks have marketed 'sugar-free' or 'no calorie' drinks for many years. These contain intense sweeteners, which are non-cariogenic (11). However, these drinks are acid and are strongly linked to erosion of dental enamel.

\section{Summary and implications for health policies}

It is clear from the above brief review that what we eat dictates whether or not we de- 
velop dental caries. Consumption of foods and drinks rich in sugar increases risk considerably. Staple starchy foods, fresh fruit, vegetables and milk are not a threat to teeth. Dietary fat and protein are not metabolised to acids within the mouth. Thus, dietary advice for oral health is completely compatible with dietary advice for general health (20). There is growing evidence that non-milk extrinsic sugars increase risk of diseases other than dental caries, either independently or via increased risk of obesity (20). Strategies to reduce sugar consumption need to be robust because there are strong forces encouraging consumption of foods and drinks high in sugar: the advertising budgets for the confectionery and soft drinks manufacturers are very large. There are signs that diets of children are improving (24) and it is worth mentioning the following initiatives. First, food and drink in school should conform to standards: confectionery is not sold and the only drinks allowed are water, milk and pure fruit juice. Second, advertisements on television displayed at times when children may be watching, should not encourage purchase and consumption of high sugar foods and drinks. Third, foods and drinks for sale must be labelled for nutrient content including sugars content. In addition, manufacturers should agree to their food products carrying 'traffic-light' labels, indicating whether a product is high (red) or low (green) in fat, salt, sugar, and energy. A tax on products high in sugars has been discussed but not yet implemented. Further information may be obtained from published reviews of diet and dental disease $(25,26)$.

\section{Fluoride}

It was stated in the first section of this article that, in many countries, caries severity reached its zenith around the 1950s and 1960s, and then declined, markedly so in several countries. This decline was almost certainly due to the increased use of fluoride, particularly the introduction of fluoride toothpastes. The story of the recognition and exploitation of fluoride's ability to prevent, partially, caries development is long and interesting (12). The 1930s and early 1940 s was a time when the inverse relationship between fluoride concentration in drinking water and dental caries experience became apparent, and the first water fluoridation scheme began in the USA in 1945. The subsequent story of water fluoridation is the subject of an article in this issue (27).

It wasn't long before fluoride was added to vehicles other than water, leading to much research and the production of many effective fluoride agents. The course of research was not always easy, as the first fluoride-containing toothpastes were ineffective due to the incompatibility between the added fluoride (as sodium fluoride) and the calciumbased abrasives (12). Alternative abrasives and fluoride compounds (e.g. sodium monofluorophosphate) overcame these difficulties. Another line of research was the application of concentrated solutions to tooth surfaces to make them more resistant to caries attack. At the same time, the success of water fluoridation led to experiments adding fluoride to domestic salt, milk, flour and even sugar - only salt and milk have stood the test of time, and these are discussed in detail in later articles in this issue $(28,29)$.

Table 4 lists the fluoride vehicles currently in use: these are grouped as those which provide fluoride 'automatically', those suitable for home care by the individual, and those which require application by a health professional. Water, salt and milk fluoridation are suitable for community prevention. Their advantages include low cost and little if any personal effort by the individual benefitting from the programme. To some extent, they can be targeted at communities most in need. These advantages have been a tremendous help in trying to combat health 
inequalities. The concentration of fluoride in water, salt or milk is decided taking background fluoride exposure and climate (since water consumption increases in hot climates) into account.

Table 4 Methods of delivering fluoride

\begin{tabular}{lll}
\hline Automatic & Home care & Professional care \\
\hline Water & Toothpaste & Solutions \\
Salt & Mouthrinse & Gels \\
Milk & Tablets & Varnishes \\
- & - & Slow-release devices \\
\hline
\end{tabular}

These three vehicles differ from the other vehicles (Table 4), in that the fluoride in water, salt and milk is ingested. This may bring added benefit but it means that only one of these so-called 'systemic' methods should be used in any community. An example of this, and the way they can be used appropriately on a population basis, can be seen in Chile. Here, the national policy is for water fluoridation and $70 \%$ of the Chilean population receives fluoridated water. In many rural areas, water fluoridation is not technically possible, and the national policy is for children in these communities to receive fluoridated milk in school. In this way, the whole population is covered. In addition, of course, the whole population is encouraged to use fluoride-containing toothpastes, since the separate preventive effects of fluoride in water and fluoride in toothpaste are additive.

The groupings in Table 4 are somewhat flexible. For example, fluoride mouthrinsing has been used, and still is, in several countries as a community preventive measure - children rinsing daily or weekly in school. Likewise, there are school-based toothbrushing programmes. School-based fluoride tablet programmes were common, especially in Eastern Europe, but there are few such programmes now.

Professional application of fluoride has a long history (12). Advantages are that ap- plications are infrequent (two to four applications per year), and you know that the application has been done. Disadvantages include: the cost is high as professional time is used, and effort to attend the appointment is needed. Professional fluoride applications, therefore, tend to be targeted at those in greatest need. Home-based and professional fluoride use will be discussed in a later article in this issue (30).

\section{Concluding comments}

From the above discussions, it can be seen that dental caries can be prevented. The fact that it remains a prevalent, expensive disease, of medical and social importance, is deeply frustrating. This preventable disease is not yet prevented. In theory, dietary control of sugar could assign caries to the 'rare disease' category, as it was in millennia past. But sugar consumption has become integral to our daily life, encouraged by massive marketing. But progress is being made: health promotion in many countries has made people aware of the desirability of reducing sugar intake and it is now less socially-acceptable to 'take sugar'. An important step was that relevant health professionals - medical, dental and dietetic - agreed what dietary messages should be. Governments have made welldocumented and authoritative statements about nutrition and diet, which have been applied at national, community and individual levels. For once, the sugar industries are 'on the back foot'. Progressive, coordinated effort will be needed to continue progress to better diets in many countries.

The picture of dental caries in the 195060 s was bleak, particularly in northern Europe and Australia; the wave continued in other European countries and South America. The widespread use of fluoride has much reduced this epidemic. This issue will discuss its use and its future. There is no doubt that fluoride is underused. Toothpaste use is less 
than half what would be required if all dentate people brushed their teeth twice a day. Water fluoridation is a low-cost, very effective, socially-equitable preventive measure yet, for a variety of reasons, it is very much underused in Europe. It is important that each country has a strategy to decrease the burden of dental caries through nutritional policy and appropriate use of fluorides.

Nutritional policy and appropriate use of fluorides is best decided at the national level. Nutritional policy for oral health is wholly compatible with nutritional policy for general health, as indicated above, and it is important that national authorities deciding such policy include expert(s) on nutrition and oral health. Part of that policy should be to ensure that dental personnel in that country are fully aware of policy, their role in promoting good nutrition in the population and know how to give nutritional advice to patients of all ages. The success of these policies needs to be monitored by regular surveillance of activities of dental personnel and by assessing the dietary habits of the population.

Decisions regarding national fluoride policy will depend on disease levels, existing fluoride exposure and resources available: these need to be assessed. Countries with large urban populations usually have centralised piped water supplies, and these would be more economic to fluoridate than water supplies for small, rural communities. The implementation of fluoridation of water, salt and milk, and the resources needed for each, will be discussed in subsequent articles in this issue. When community preventive schemes are introduced, it is important that adequate resources are identified to measure the effectiveness of these programmes: WHO recommends that $10 \%$ of the budget is devoted to evaluation. It is important to recognise that efforts to improve nutrition and maximise the appropriate use of fluoride are not alternatives; both are important to the improvement of oral health.
Conflict of interest: The author declares that he has no conflict of interest.

\section{References}

1. Marthaler TM. Changes in dental caries 19532003. Caries Res. 2004;38:173-81.

2. Petersen PE. The World Oral Health Report 2003: continuous improvement of oral health in the 21st century - the approach of the WHO Global Oral Health Programme. Community Dent Oral Epidemiol. 2003;31(Suppl 1):3-24.

3. Petersen PE, Kandelman D, Arpin S, Ogawa H. Global oral health of older people - call for public health action. Community Dent Health. 2010;27(Suppl 2):257-68.

4. Rugg-Gunn AJ, Carmichael CL, French AD, Furness JA. Fluoridation in Newcastle and Northumberland: a clinical study of 5-year-old children. $\mathrm{Br}$ Dent J. 1977;142:395-402.

5. Petersen PE. World Health Organization global policy for improvement of oral health - World Health Assembly 2007. Int Dent J. 2008;58:115-21.

6. Patel R. The state of oral health in Europe. Report commissioned by the Platform for Better Oral Health in Europe; 2012. [cited 2013 January 25]. Available from: http://www.oralhealthplatform. eu/sites/default/files/field/document/Report\%20 -\%20the $\% 20$ State $\% 20$ of\%20Oral\%20Health $\% 20$ in\%20Europe.pdf

7. Nyvad B. The role of oral hygiene. In: Fejerskov O, Kidd EAM, editors. Dental caries. Oxford: Blackwell Munksgaard; 2003. p. 171-7.

8. Scheie AAa. The role of antimicrobials. In: Fejerskov O, Kidd EAM, editors. Dental caries. Oxford: Blackwell Munksgaard; 2003. p. 179-88.

9. Meurman JH. Probiotics and oral health. In: Wilson $\mathrm{M}$, editor. Food constituents and oral health. Cambridge: Woodhead; 2009. p. 421-32.

10. Petersson LG, Magnusson K, Hakestam U, Baigi A, Twetman S. Reversal of primary root caries lesions after daily intake of milk supplemented with fluoride and probiotic lactobacilli in older adults. Acta Odont Scand. 2011;69:321-7.

11. Rugg-Gunn AJ. Nutrition and dental health. Oxford: Oxford Medical Publications; 1993.

12. Murray JJ, Rugg-Gunn AJ, Jenkins GN. Fluorides in caries prevention. 3rd ed. Oxford: ButterworthHeinemann; 1991.

13. Rugg-Gunn AJ. Dental caries. In: Welbury RR, editor. Paediatric dentistry. 2nd ed. Oxford: Oxford Medical Publications; 2001. p. 95-114. 
14. Wang X, Willing MC, Marazita ML, Wendell S, Warren JJ, Broffitt B, et al. Genetic and environmental factors associated with dental caries in children: the Iowa fluoride study. Caries Res. 2012;46:177-84.

15. Kite OW, Shaw JH, Sognnaes RF. The prevention of experimental tooth decay by tube-feeding. J Nutrit. 1950;42:89-103.

16. Orland FJ, Blayney JR, Harrison RW, Reyniers JA, Trexler PC, Wagner M, et al. Use of the germ-free animal technic in the study of experimental dental caries. J Dent Res. 1954;33:147-74.

17. Stephan RM. Changes in hydrogen-ion concentration on tooth surfaces and in carious lesions. J Am Dent Ass. 1940;27:718-23.

18. Jay P. The role of sugar in the etiology of dental caries. J Am Dent Ass. 1940;27:393-6.

19. Department of Health. Dietary sugars and human disease. Report on health and social subjects 37. London: HMSO; 1989.

20. World Health Organization. Diet, nutrition and the prevention of chronic diseases. Report of a joint WHO/FAO expert consultation. WHO technical report series 916. Geneva: WHO; 2003.

21. Rugg-Gunn AJ, Adamson AJ, Appleton DR, Butler TJ, Hackett AF. Sugars consumption by 379 11-12 year old English children in 1990 compared with results in 1980. J Hum Nutr Diet. 1993;6:419-31.
22. Maguire A, Rugg-Gunn AJ. Xylitol and caries prevention - is it the magic bullet? Br Dent J. 2003;194:429-36.

23. Mäkinen KK. Oral care gum products. In: Wilson M, editor. Food constituents and oral health. Cambridge: Woodhead; 2009. p. 433-54.

24. Fletcher ES, Rugg-Gunn AJ, Matthews JNS, Hackett A, Moynihan PJ, Mathers JC, et al. Changes over 20 years in macronutrient intake and body mass index in 11- to 12-year-old adolescents living in Northumberland. Br J Nutr. 2004;92:321-33.

25. Moynihan PJ. Dental Disease. In: Geissler CA, Powers HJ, editors. Human nutrition. 11th ed. Edinburgh: Elsevier; 2005. p. 461-76.

26. Moynihan PJ. Dietary advice in dental practice. $\mathrm{Br}$ Dent J. 2002;93:563-8.

27. Harding MA, O’Mullane DM. Water fluoridation and oral health. Acta Med Acad. 2013;42:131-39.

28. Marthaler TM. Salt fluoridation for the prevention of dental caries - its role and potential. Acta Med Acad. 2013;42:140-55.

29. Bánóczy J, Rugg-Gunn AJ, Woodward M. Milk fluoridation for the prevention of dental caries. Acta Med Acad. 2013;42:156-67.

30. Rugg-Gunn AJ, Bánóczy J. Fluoride dentrifices and fluoride mouthrinses for home use. Acta Med Acad. 2013;42:168-78. 


\title{
Water fluoridation and oral health
}

\author{
Máiréad Antoinette Harding ${ }^{1,2}$, Denis Martin O’Mullane ${ }^{1}$
}

\author{
${ }^{1}$ Oral Health Services Research Centre \\ Cork University Dental School and \\ Hospital, Wilton, Cork, Ireland \\ ${ }^{2}$ HSE-South, Dental Clinic, Health Centre \\ Innishmore, Ballincollig, Co Cork, Ireland \\ Corresponding author: \\ Máiréad Antoinette Harding \\ Oral Health Services Research Centre \\ Cork University Dental \\ School and Hospital \\ Wilton, Cork, Ireland \\ m.harding@ucc.ie \\ Tel.: + 353214901210 \\ Fax.: + 353214545391
}

Received: 28 February 2013

Accepted: 18 April 2013

Copyright () 2013 by

Academy of Sciences and Arts

of Bosnia and Herzegovina.

E-mail for permission to publish:

amabih@anubih.ba

\begin{abstract}
Water fluoridation, is the controlled addition of fluoride to the water supply, with the aim of reducing the prevalence of dental caries. Current estimates suggest that approximately 370 million people in 27 countries consume fluoridated water, with an additional 50 million consuming water in which fluoride is naturally occurring. A pre-eruptive effect of fluoride exists in reducing caries levels in pit and fissure surfaces of permanent teeth and fluoride concentrated in plaque and saliva inhibits the demineralisation of sound enamel and enhances the remineralisation of demineralised enamel. A large number of studies conducted worldwide demonstrate the effectiveness of water fluoridation. Objections to water fluoridation have been raised since its inception and centre mainly on safety and autonomy. Systematic reviews of the safety and efficacy of water fluoridation attest to its safety and efficacy; dental fluorosis identified as the only adverse outcome. Conclusion: Water fluoridation is an effective safe means of preventing dental caries, reaching all populations, irrespective of the presence of other dental services. Regular monitoring of dental caries and fluorosis is essential particularly with the lifelong challenge which dental caries presents.
\end{abstract}

Key words: Water fluoridation, Effectiveness, Dental caries, Fluorosis.

\section{Introduction}

Dental Caries (tooth decay); a transmissible infectious disease with a multifactorial aetiology has affected individuals for centuries at least since the seventh century and the Iron Age (1). Change in the distribution of dental caries intra-orally has occurred, as has the dominant paradigm in managing dental caries. A much greater emphasis is now being encouraged towards prevention rather than curative care. Community factors are currently the focus of considerable research internationally. Social gradients in caries are demonstrated and neighbour- hood factors such as where we live and the foods and the fluorides we have access to, all exert an impact on the development of the disease (2). Dental caries is still a major oral health problem in many established economies, affecting $60-90 \%$ of schoolchildren and the vast majority of adults. It is also a prevalent oral disease in several Asian and Latin-American countries, while it appears to be less common and less severe in many African countries (3). In the US it has been described as the most common chronic disease of childhood (4). Untreated dental caries can lead to pain, infection, impaired 
function, poor aesthetics, and diminished quality of life, which equate to a significant human, financial, psychological and emotional cost.

Water fluoridation is described as the controlled addition of fluoride to the water supply with the aim of reducing the prevalence of dental caries. Fluoride can also occur naturally in some water supplies. Current estimates are that 370 million people in 27 countries are currently supplied with artificially fluoridated water and 50 million around the world are drinking naturally fluoridated water (5).

This paper will discuss water fluoridation under the following headings: Background, the mode of action, the effectiveness, the risks and benefits, the monitoring of water fluoridation and the legislative nature of providing communities with water fluoridation.

In the review baseline and subsequent national oral health surveys conducted in Ireland are included to demonstrate the effectiveness of water fluoridation and the challenges to water fluoridation; in the Republic of Ireland (RoI) $73 \%$ of the population presently benefit from water fluoridation. Thus providing an appropriate example for Europe $(6,7,8)$.

The terms part per million, ppm and $\mathrm{mg} / \mathrm{l}$ are used rather than the SI unit for fluoride in water $\mu \mathrm{g} / \mathrm{ml}$, to conform to previous research.

\section{Background}

Water fluoridation is an ideal public health measure in reducing dental caries; since its effectiveness does not require conscious daily cooperation from individuals (9) The beneficial effects of natural water fluoridation in caries prevention was identified in the first part of the $20^{\text {th }}$ century and is undoubtedly a significant landmark in dentistry $(10,11,12)$, culminating in the introduction of artificial water fluoridation to the pioneering public health city of Grand Rapids, Michigan (13). In the second part of the $20^{\text {th }}$ century, to address the high prevalence of dental caries water fluoridation was introduced to many countries, including Ireland, Australia, Hong Kong, Israel, New Zealand, Singapore, and the UK.

\section{Mode of Action}

The mode of action of fluoride in the prevention of dental caries is predominantly posteruptive; however, the pre-eruptive effect of ingested fluoride is also important. Findings from Australia, the Netherlands and Maryland support the pre-eruptive effect of fluoride in reducing caries levels in pit and fissure surfaces of permanent teeth. Research has also indicated that exposure to fluoridated water from birth produces the maximum benefit $(14,15)$. What is clear is that a constant low level of fluoride ion in saliva and plaque fluid reduces the rates of enamel demineralisation during the caries process and promotes the remineralisation of early caries lesions $(16,17)$. Fluoride concentrated in plaque and saliva inhibits the demineralisation of sound enamel and enhances the remineralisation of demineralised enamel.

\section{The effectiveness of water fluoridation}

The Centers for Disease Control and Prevention (CDC) have recognised water fluoridation as one of the ten great public health measures of the twentieth century (12). The extensive international research demonstrating the effectiveness of water fluoridation is summarised in a number of important texts $(18,19)$, recently Rugg-Gunn and Do (20) presented the international studies attesting to the effectiveness water fluoridation published between 1990 and 2010, the reader is referred to these sources for a review of the many international studies. The number of studies which were conducted 
since 1990 has declined; newer studies have tended to be pragmatic with the statistical analyses taking account of confounding factors $(20,21)$. Despite an overall reduction in the number of countries and studies represented the number of studies from Brazil and Australia had increased, both countries having extensive water fluoridation $(5,20)$. All studies demonstrate a similar positive reduction in per cent caries reduction.

Sources suggest that water fluoridation is not only effective in childhood but also into adulthood $(22,23)$. Water fluoridation combined with toothpaste use could be more effective than either alone (24).

\section{Water fluoridation in Ireland}

The fluoridation of water supplies in Ireland is indicative of the effectiveness, the benefits of, the required monitoring and challenges that may occur after implementation (25). In the mid twentieth century the RoI required a solution to the effects of widespread dental caries and introduced water fluoridation to Dublin on July $15^{\text {th }} 1964$, and to Cork in May 1965 the planned introduction being delayed by some four years due to legal challenges in both the High and Supreme Courts (26). By 1970 the majority of cities and larger towns were fluoridated. Under the legislation directing water fluoridation (27) provision was made that, before implementation of the Act a baseline survey of caries levels among children and adolescents would be undertaken (6). The Act also importantly stipulated that regular caries surveys be undertaken "whenever and as often as the Minister requires" to monitor the effectiveness of fluoridation of water supplies in controlling dental caries.

The baseline surveys conducted prior to water fluoridation indicate a high caries experience; this was recorded as the number of teeth which were decayed, missing or filled because of tooth decay. They were recorded using the $\mathrm{dmf} / \mathrm{DMF}$ index for both the primary (baby teeth) (dmf), and permanent (adult) (DMF) dentitions in 5-year-old to 15 -year-old children $(6,28)$ (Table 1$)$. Once the fluoridation of water supplies commenced the concentration of fluoride in water was set in the range 0.8 to $1.0 \mathrm{ppm}$, with a target of $0.9 \mathrm{ppm}$.

\section{National survey of children's oral health (Republic of Ireland) - 1983-84}

In 1982 the Department of Health in the RoI commissioned a National Survey of Children's Dental Health, the primary aim of which was to measure the effectiveness of water fluoridation on a countrywide basis, it was also decided that levels of enamel fluorosis would be recorded, using internationally accepted indices $(28,29)$. Random sam-

Table 1 Mean dmft* in five-year-olds, and DMFT* in 15-year-olds, in fluoridated communities (full FI) in the Republic of Ireland in 1984 and 2002, and in non-fluridated communities (non FI) in the Republic of Ireland and Northern Ireland in the 1960s, 1983-84 and $2002(6,7,8)$

\begin{tabular}{lllllll}
\hline & \multicolumn{5}{l}{ 5-Year-Olds } & \multicolumn{3}{l}{ 15-Year-Olds } \\
\cline { 2 - 7 } Year & Full FI & Non FI & & Full Fl & Non FI \\
\cline { 2 - 7 } & Rol & Rol & NI & Rol & Rol & NI \\
\hline 1960 & - & 5.6 & 4.8 & - & 8.2 & 10.6 \\
$1983-1984$ & 1.8 & 3.0 & 4.5 & 4.1 & 5.4 & 9.2 \\
2002 & 1.3 & 1.7 & 1.8 & 2.1 & 3.2 & 3.6 \\
\hline
\end{tabular}

$\mathrm{FI}=$ fluoridated; Rol = Republic of Ireland; $\mathrm{NI}=$ Northern Ireland; $\mathrm{dmf}=$ decayed missing filled primary (teeth). DMF refers to permanent teeth. 
ples of children who were lifetime residents of either fluoridated or non-fluoridated areas and aged five, eight, 12 or 15 years-old were examined by 10 examiner/recorder teams (7). The criteria adopted for dental caries examination were similar to those used in the baseline studies of 1961-1963 (6) thus permitting comparison. The results indicated a decline in caries levels for children in both fluoridated and non-fluoridated areas; the decline being considerably greater in fluoridated areas, fluorosis was measured using Dean's index of fluorosis, the teeth scored for fluorosis were the upper permanent incisors (29). The children who were resident in non-fluoridated areas had a significantly higher dmf/ DMF than those in fluoridated areas (Table 1).

The observed downward trend in dental caries has been noted in many international studies; the advent of fluoridated toothpastes in the 1970's providing a valued contribution (30). In the national survey in 1983-'84 (7) the prevalence of fluorosis was low, with $94 \%$ of children in fully fluoridated communities having normal enamel according to Dean's Index (29), compared with 98\% among eight-year-old children in nonfluoridated communities (Table 2). Only fluorosis grades of 'questionable' and 'very mild' were recorded in the survey $(7,8,31)$.

\section{The North south survey of children's oral health - 2002}

In 2000 under a contract for the evaluation of oral health services the Department of Health commissioned a further national survey of children's dental health, with the aim of monitoring the effectiveness of water fluoridation (8).The study included a contemporaneous survey of children's dental health in Northern Ireland (NI), where water fluoridation has not been introduced (31). The diagnostic criteria for both caries and dental fluorosis were the same as used in the 1984 study (7). It was seen that in the period from 1983-1984 to 2002 there was a substantial reduction in dental caries in both fluoridated and non-fluoridated communities in the RoI, and in the non-fluoridated population of NI; the reduction in the period from 1983 ' 84 to 2002 , is greater in fluoridated communities. In the five-year-old age group, the mean dmft among the lifetime residents of fluoridated communities in the RoI declined from 1.8 in $1983-{ }^{-} 84$ to 1.3 in 2002 , the corresponding figures for five-year-old children in non-fluoridated areas in the RoI were 3.0 and 1.7, and in NI were 4.5 and 1.8 respectively. Similar trends are apparent in the figures recorded for caries among 15-year-olds in both jurisdictions (Table 1).

Table 2 Dean's Index of Fluorosis*- \% of eight-year-olds affected according to fluoridation status in the Republic of Ireland and Northern Ireland in 2002 and 1984 (7, 8)

\begin{tabular}{llllll}
\hline \multirow{2}{*}{ Eight-Year-Olds } & Full FI & Non FI & Full FI & Non FI & Non FI \\
\cline { 2 - 6 } & Rol & Rol & Rol & Rol & NI \\
\cline { 2 - 6 } & $1984(\mathrm{a})$ & $1984(\mathrm{~b})$ & $2002(\mathrm{c})$ & $2002(\mathrm{~d})$ & $2002(\mathrm{e})$ \\
\hline Normal & 94 & 98 & 76 & 90 & 90 \\
Questionable & 5 & 2 & 11 & 7 & 6 \\
Very Mild & 1 & 0 & 8 & 2 & 3 \\
Mild & 0 & 0 & 4 & 0 & 0 \\
Moderate & 0 & 0 & 0 & 0 & 0 \\
Severe & 0 & 0 & 0 & 0 & 0 \\
\hline
\end{tabular}

*Scores relate to permanent maxillary incisor teeth; Rol= Republic of Ireland; $\mathrm{N}=$ Northern Ireland; The difference between a and c, $\mathrm{c}$ and $\mathrm{d}$ and $c$ and e were significant $(p<0.0001)$. 
The inverse occurred with the prevalence of dental fluorosis and fluorosis increased in the RoI between 1983-1984 and 2002, particularly in residents of communities with water fluoridation. In 1983-'84, ninety-four percent of children residing in fluoridated communities in the RoI had normal enamel; this figure had reduced to $76 \%$ in 2002 (Table 2). The figures for 'questionable,' 'very mild' and 'mild' fluorosis in 1983-1984 were $5 \%, 1 \%$ and zero, respectively; these figures had increased in 2002 to $11 \%, 8 \%$ and $4 \%$, respectively. The increasing prevalence of fluorosis was also identified internationally $(32,33)$.

\section{The benefit of water fluoridation}

Water fluoridation has been the subject of rigorous reviews of late and has been recognised as safe and as the most effective method of reaching the whole population irrespective of access to dental services in this way each individual can benefit without the need for active participation $(24,34,35)$. In addition the review of $\mathrm{McDonagh}$ et al. (24) suggested water fluoridation conferred a benefit over and above the use of fluoride containing toothpastes alone. The process of water fluoridation has been endorsed by the world's leading science and health organisations including the WHO (36), IADR (International Association of Dental Research) and FDI (World Dental Federation), with the benefits available to both child and adult $(22,23)$. Griffin et al. (37) showed that for the US water fluoridation delivered significant cost savings.

\section{The risk of water fluoridation}

Dental fluorosis is recognised as a consequence of consuming fluoridated water supplies.

It arises as a result of a long-term intake of fluoride during the preeruptive develop- ment of teeth. It is a hypomineralisation of enamel characterised by an increased surface and subsurface porosity causing opacity, pitting or staining of the enamel (38).

However water fluoridation since its initiation has attracted hostile publicity, those who do not put a value on water fluoridation caution that it is; costly and not effective, that it impacts negatively on general health; causes objectionable dental fluorosis and that it is a violation of medical ethics and the rights of the individual (39). Thus the very core of its capacity to promote prevention to the whole population is challenged.

All of the reviews conducted on water fluoridation have acknowledged that fluorosis occurs to some degree with water fluoridation, and fluorosis was identified as the only adverse effect of fluoridation (33). The likelihood of fluorosis occurring was identified at the very outset, for it was McKay's observation of the Colorado 'brown stain' that led to the identification of the beneficial effect of fluoride in the prevention of dental caries and was acknowledged in the work of Dean and the '21 cities study' (10). The environmental concerns which have been raised with regard to fluoride were recently addressed in the report of the European Commission's Scientific Committee on Health and Environmental Risks (SCHER) (40). The committee did not identify any evidence of negative environmental impacts from community water fluoridation. Ethical concerns were addressed by the Nuffield Council on Bioethics (41, 42, 43). Reviews conducted in the US, Australia, and Canada arrived at similar conclusions $(35,44,45)$. Nevertheless it is crucial that on-going surveillance of general health be maintained in fluoridated and non-fluoridated communities. The structured use of health registers, for example cancer and hip fracture registers, are an important source of information for this purpose. 


\section{Monitoring}

The studies conducted in Ireland $(7,8)$ established there was a decline in dental caries after the fluoridation of water supplies and also an increase in dental fluorosis. Good practice recommends the recording of the fluoride concentration in water supplies on a regular basis, daily, weekly, monthly and strategies must be in place to notify the relevant authorities of the measurements that are recorded. Audit is possible when the agency fluoridating supplies is not the same agency. In Ireland the sanitary authorities have responsibility for the addition of fluoride to water supplies while the health authorities and environmental protection agency have responsibility for monitoring the concentration of fluoride in supplies (26, 46). This also ensures agencies are compliant with legislation and regulation.

Regular monitoring has led to changes in fluoride concentration internationally. When the prevalence and severity of fluorosis between the two national surveys $(7,8)$ was compared in Ireland $(7,8)$, (Table 2 ), the prevalence had increased. Consequent on these findings in 2007 the level of fluoride in drinking water was reduced from a range of 0.8 to $1.0 \mathrm{ppm}$, with a target of $0.9 \mathrm{ppm}$, to a range of 0.6 to $0.8 \mathrm{ppm}$, with a target of 0.7 ppm (47). In addition, recommendations for the use of fluoride toothpaste by infants and young children were also introduced (34). Recommendations with regard to toothpaste were made as the inappropriate use of fluoride toothpaste in young children who may not be able to expectorate it adequately is a major risk factor in fluorosis $(38,48,49)$.

A downward revision of the concentration of fluoride in water supplies has occurred in other jurisdictions to balance the availability of fluorides from other sources, such as fluoridated toothpastes. The Department of Health and Human Services in the US has recommended water fluoridation at
$0.7 \mathrm{mg} / \mathrm{l}(\mathrm{ppm})$, rather than the previous range $0.7 \mathrm{mg} / \mathrm{l}-1.2 \mathrm{mg} / \mathrm{l}$, (ppm) to take account of other sources from which communities may receive fluorides (50). In Canada the concentration of $0.7 \mathrm{mg} / \mathrm{l}$ (ppm) of fluoride has been set moving from the previous range of 0.8 to $1.0 \mathrm{mg} / \mathrm{l}$ (ppm) (51) while in Australia, levels have remained unchanged, since the current research in Australia into caries prevention and fluorosis suggests maintaining the status quo. Some Asian, tropical and sub-tropical regions have reviewed the concentrations at which water is fluoridated and have agreed an upper and lower limit of $1 \mathrm{mg} / \mathrm{l}$ and $0.5 \mathrm{mg} / \mathrm{l}$ (ppm) respectively.

Naturally occurring high fluoride water supplies occur around the world and defluoridation if required is possible (18), some of the methods which can be used for defluoridation are to blend waters with high fluoride concentration with waters of low concentration in addition technologies such as reverse osmosis, electrodialysis and distillation are available in the market. The fluoridation plants must have an effective fail-safe system with well-defined limits for the precision of measurements (52). A concentration of $1.5 \mathrm{mg} / \mathrm{l}(1.5 \mathrm{ppm})$ is accepted as the Maximum Acceptable Concentration (MAC) of artificially fluoridated supplies.

\section{Legislation}

Legislation providing for water fluoridation can be of two types. It may be mandatory, requiring a ministry of health or communities of a certain size to fluoridate their public water supplies if it is below the accepted fluoride level; this is the type of legislation in Ireland. Alternatively, it may be of the permissive or enabling type, empowering the ministry of health or a local government to institute fluoridation. Some countries and jurisdictions require consultations with the community and to consider such consultations prior to proceeding, such as in the UK. 


\section{Discussion}

In this article the authors have brought together the experience of and the challenges to water fluoridation using the experiences in the RoI for examples. They have also considered why it remains an effective component of prevention and oral health policy. Emerging evidence suggests that the declining caries levels which excited oral health professionals through the nineties and early 2000's may have plateaued. Internationally established economies are tending towards a more energy dense, refined carbohydrate diet, which may become more challenging in the delicate balance in preventing dental caries and dental fluorosis, and promoting oral health. The National Health and Medical Research Council in Australia (35) concluded: the existing body of evidence strongly suggests that water fluoridation is beneficial at reducing dental caries'. For most studies the consistent measure of effect to indicate the effectiveness of water fluoridation is the dmf/DMFT index (20), scientifically this makes sense and permits comparison with relative ease. Perhaps going forward ways of demonstrating effectiveness in terms of the distress and misery avoided, capturing children's ability to develop a positive association with oral health should be considered. The emotional impact of dental caries is significant and apparent on a daily basis to a significant number of families and dental personnel.

\section{Conclusion}

Water fluoridation is an effective safe means of preventing dental caries, reaching all populations, irrespective of the presence of other dental services. The monitoring of dental caries and dental fluorosis is the cornerstone of good public health practice and is essential particularly when the lifelong challenge which dental caries presents is considered.
Future research must consider the challenges in reporting appropriate outcomes for both dental caries and dental fluorosis and the means of overcoming the challenges in the design, conduct and reporting of future work.

Authors' contributions: Conception and design: DOM, MH; Acquisition, analysis and interpretation of data: DOM, MH; Drafting the article: DOM, $\mathrm{MH}$; Revising it critically for important intellectual content: DOM, MH.

Conflict of interest: The authors declare that they have no conflict of interest.

\section{References}

1. Moore WY. The distribution of dental caries in ancient British populations. Caries Res. 1973;(7):139-53.

2. Sgan-Cohen HD, Evans RW, Whelton H, Villena RS, Mac Dougall M, Williams D. IADRGOHIRA Steering and Task Groups. IADR Global Oral Health Inequalities Research Agenda (IADR-GOHIRA $\left.{ }^{\oplus}\right)$. A call to action. J Dent Res. 2013;(92):209-11.

3. World Health Organisation. Oral disease burdens and common risk factors: WHO; 2012. [cited 2013 Jan 31]. Available from: http://www.who.int/oral_ health/disease_burden/global/en/index.html.

4. Oral Health in America. A Report of the Surgeon General. Rockville, MD: US Dept. of Health and Human Services, National Institutes of Health, National Institute of Dental and Craniofacial Research; 2012. p. 2.

5. British Fluoridation Society (BFS): One in a million - the facts about water fluoridation, 3rd ed. [cited 2013 Jan 19]. Available from: http://www. bfsweb.org/onemillion/onemillion2012.html.

6. Minister for Health: Reports on the incidence of dental caries in school children and on the analyses of public piped water supplies in the different counties, 1961-1965. Dublin: Stationery Office; 1965.

7. O’Mullane DM, Clarkson J, Holland T, O'Hickey S, Whelton HP. Children's Dental Health in Ireland 1984. Dublin: Stationery Office; 1986.

8. Whelton H, Crowley E, O'Mullane D, Harding M, Guiney H, Cronin M, et al. North South Survey of Children's Oral Health in Ireland 2002. Dublin: Brunswick Press Ltd; 2006 [cited 2013 Jan 20]. Available from: www.dohc.ie/publications/oral_ health.html. 
9. Centers for Disease Control and Prevention (CDC). Populations receiving optimally fluoridated public drinking water-United States. MMWR Morb Mortal Wkly Rep. 2002;(51):144-7.

10. Dean HT, Arnold FA, Elvove E. Domestic water and dental caries. Additional studies of the relation of fluoride domestic waters to dental caries experience in 4,425 white children aged 12-14 years of 13 cities in 4 states. Public Health Rep. 1942;(57):1155-79.

11. Dean HT, Arnold FA, Jay P, Knutson JW. Studies on mass control of dental caries through fluoridation of the public water supply. Public Health Rep. 1950;(65):1403-8.

12. Centers for Disease Control and Prevention (CDC). Achievements in public health, 19901999: fluoridation of drinking water to prevent dental caries. MMWR Morb Mortal Wkly Rep.1999;(48):933-40.

13. Centers for Disease Control and Prevention (CDC). CDC Honours 65 Years of Community Water Fluoridation; 2010. [cited 2013 Jan 16]. Available from: http://www.cdc.gov/fluoridation/65_years.htm.

14. Groeneveld A, Van Eck AA, Backer-Dirks O. Fluoride in caries prevention: is the effect pre- or post- eruptive? J Dent Res. 1990;69 Spec No: 7515:820-3.

15. Singh KA, Spencer AJ, Brennan DS. Effects of water fluoride exposure at crown completion and maturation on caries of first permanent first molars. Caries Res. 2007;(41):34-42.

16. Fejerskov O, Thylstrup A, Larsen MJ. Rational use of fluoride in caries prevention: A concept based on various cariostatic mechanisms. Acta Odontol Scand. 1981;(39):241-9.

17. Featherstone JD. Prevention and reversal of dental caries: role of low level fluoride. Community Dent Oral Epidemiol. 1999;(27):31-40.

18. World Health Organisation. Appropriate use of fluorides for human health. Geneva: World Health Organisation; 1986.

19. Murray JJ, Rugg-Gunn AJ, Jenkins GN. Fluorides in caries prevention, $3^{\text {rd }}$ ed. Oxford: ButterfieldHeinemann; 1991.

20. Rugg-Gunn A and Do L. Effectiveness of water fluoridation in caries prevention. Community Dent Oral Epidemiol. 2012;40(Suppl 2):S55-64.

21. O'Mullane DM, James P, Whelton H, Parnell C. Methodological issues in oral health research: intervention studies. Community Dent Oral Epidemiol. 2012;40(Suppl 1):S15-20.

22. Neidell M, Herzog K, Glied S. The Association between community water fluoridation and adult tooth loss. Am J of Pub Health. 2010;(100):1980-5.
23. Slade GD, Sanders AE, Do L, Roberts-Thomson K, Spencer AJ. Effects of fluoridated drinking water on dental caries in Australian adults. J Dent Res. 2013;(92):376-82.

24. McDonagh MS, Whiting PF, Wilson PM, Sutton AJ, Chestnutt I, Cooper J, et al. Systematic review of water fluoridation. BMJ. 2000;321(7265):855-9.

25. O'Grady P. In the public good. J Ir Dent Assoc. 2012;58(3 Suppl)S4-5.

26. Clarkson J, McLoughlin J, O’Hickey S. Water fluoridation in Ireland - A success story. J Dent Res. 2003;(82):334-7.

27. Health (Fluoridation of Water Supplies) Act, 1960. Dublin: Stationery Office; 1960.

28. Klein H, Palmer E, Knutson JW. Studies on Dental Caries: Dental status and dental needs of elementary school children. Public Health Rep. 1938;(53):751-65.

29. Dean HT. The investigation of physiological effects by the epidemiological method. In: Moulton FR, ed. Fluorine and dental health. Washington DC: American Association for the Advancement of Science; 1942. p. 23-71.

30. Petersson G, Bratthall D. The caries decline: A review of the reviews. Eur J Oral Sci. 2007;(104):436-43.

31. Whelton H, Crowley E, O’Mullane D, Donaldson M, Cronin M, Kelleher V. Dental caries and enamel fluorosis among the fluoridated population in the Republic of Ireland and non-fluoridated population in Northern Ireland in 2002. Community Dent Health. 2007;(23):37-43.

32. Fomon SJ, Ekstrand J, Ekhard E, Ziegler D. Fluoride intake and prevalence of dental fluorosis: Trends in fluoride intake with special attention to infants: Review and commentary. J Pub Health Dent. 2000;(60):131-9.

33. Pendrys DG, Haugejorden O, Bardsen A, Wang NJ, Gustavsen F. The risk of enamel fluorosis and caries among Norwegian children: implications for Norway and the United States. J Am Dent Assoc. 2010;(141):401-14.

34. Report of Forum on Fluoridation. Dept. of Health [cited 2013 Feb 11]. Available from: http://www. dohc.ie/publications/pdf/fluoridation_forum.pdf.

35. National Health and Medical Research Council. A systematic review of the efficacy and safety of fluoridation. Canberra, Australian Government; 2007. [cited 2013 Feb 11]. Available from: http://www. nhmrc.gov.au/_files_nhmrc/publications/attachments/eh41_1.pdf.

36. Petersen PE. The World Oral Health Report 2003: continuous improvement of oral health in the 21 st century - the approach of the WHO Global Oral 
Health Programme. Community Dent Oral Epidemiol. 2003;(1):3-23.

37. Griffin SO, Jones K, Tomar SL. An economic evaluation of community water fluoridation. J Public Health Dent. 2001;(61):78-86.

38. Browne D, Whelton H, O’Mullane D. Fluoride metabolism and fluorosis. J Dent. 2005;(33):177-86.

39. Melbye MLR, Armfield JM The dentist's role in promoting community water fluoridation: A call to action for dentists and educators. JADA. 2013;(144):65-75.

40. EU Scientific Committee on Health and Environmental Risks (SCHER). Critical review of any new evidence on the hazard profile, health effects, and human exposure to fluoride and the fluoridating agents of drinking water; 2011 [cited 2013 Feb 4]. Available from: http://ec.europa.eu/health/ scientific_committees/environmental_risks/index_en.htm.

41. Nuffield Council on Bioethics. Public Health: Ethical Issues. London: Nuffield Council on Bioethics; 2007.

42. Mullen J. History of water fluoridation. BDJ. 2005;(199);1-4.

43. Mullen J. Defending fluoridation. J Ir Dent Assoc. 2012;58(3 Suppl):S9.

44. Centers for Disease Control and Prevention CDC Oral Health Division. Oral Health Resources; 2013. [cited 2013 Feb 3]. Available from: http:// www.cdc.gov/oralhealth/.

45. Guidelines for Canadian Drinking Water Quality. Guideline Technical Document Fluoride. FederalProvincial-Territorial Committee on Drinking Water of the Federal-Provincial-Territorial Com- mittee on Health and the Environment. Ottawa, Ontario; 2010. [cited 2013 Feb 3]. Available from: http://www.hc-sc.gc.ca/ewh-semt/alt_formats/ hecs-sesc/pdf/pubs/water-eau/2011-fluoridefluorure/2011-fluoride-fluorure-eng.pdf.

46. European Communities (Drinking Water) (No.2) Regulations S.I. No. 278 / 2007). Government of Ireland; 2007. [cited 2013 Aug 07]. Available from: http://www.irishstatutebook.ie/2007/en/si/0278. html.

47. Fluoridation of Water Supplies Regulations. S.I. No. 42/2007. Government of Ireland; 2007. [cited 2013 Jan 24]. Available from: http://www.irishstatutebook.ie/2007/en/si/0042.html.

48. Pendrys DG, Stamm JW. Relationship of total fluoride intake to beneficial effects and enamel fluorosis. J Dent Res. 1990;69(Special Issue):529-38.

49. Harding MA, Whelton H, O'Mullane DM, Cronin M, Warren JJ. Primary tooth fluorosis in 5-yearold schoolchildren in Ireland. Eur J Paediatr Dent. 2005;(6):155-61.

50. Centers for Disease Control and Prevention (CDC), Division of Oral Health, Changes proposed to national fluoridation level. [cited 2013 Feb 11]. Available from: http://www.cdc.gov/oralhealth/.

51. Findings and recommendations of the Fluoride Expert Panel. Health Canada; 2007. [cited 2013 Feb 2]. Available from: http://www.hc-sc. gc.ca/ewh-semt/pubs/water-eau/2008-fluoridefluorure/index-eng.php.

52. Fawell J, Bailey K, Chilton J, Dahi E, Fewtrell L, Magara Y. Fluoride in drinking water. WHO. London: IWA Publishing; 2006. 